\title{
Occurrence, mineralogy and geochemistry of fracture fillings in tight sandstones and their constraints on multiple-stage tectonic fluids: An example from the Kuqa foreland thrust belt, Tarim Basin, China \\ Chun Liu
}

PetroChina Hangzhou Research Institute of Geology

(No.920, Xixi Road, Hangzhou 310023, China)

\begin{abstract}
Deep sandstone reservoirs of the Lower Cretaceous Bashijiqike Formation in the Kuqa foreland thrust belt, Tarim Basin in NW China provide a good example for studying tectonic fluid activities in tight sandstone reservoirs and their effects on reservoir quality. Three types of fractures can be identified in the sandstone reservoirs: full-filling fractures, semi-filling fractures and small-filling fractures. The fracture fillings are mainly composed of ferriferous dolomite, dolomite, calcite, quartz and anhydrite. The ferriferous dolomites are mainly accumulated in the full-filling fractures. The dolomites mainly occur in the semi-filling fractures and full-filling fractures. The calcites often occur in the full-filling fractures, semi-filling fractures and small-filling fractures. The quartz is distributed at the edge of the semi-filling fractures. Anhydrite is often associated with dolomite and calcite. Contents of $\mathrm{Co}, \mathrm{Ni}$ and $\mathrm{V}$ in the ferruginous dolomite are generally higher than that in the dolomite, calcite and anhydrite, and contents of $\Sigma$ REE, $\Sigma$ LREE, Ce and Eu are gradually decreasing in turn from the ferruginous dolomites to the dolomites, and to the calcites. The $\delta^{13} \mathrm{C}$ of the ferruginous dolomite, dolomite and calcite ranges from $3.78 \%$ to $-1.49 \%$ with an average value of $-2.82 \%$, and their $\delta^{18} \mathrm{O}$ ranges from $-16.43 \%$ to $-12.3 \%$ with an average value of $-14.62 \%$. The full-filling fractures, ferruginous
\end{abstract}


dolomite, semi-filling fractures, quartz, dolomite, small-filling fractures, calcite and anhydrite successively occur from early to late stage. The carbonate minerals in the fractures are formed in freshwater which is oxidizing and has low salinity. The formation temperature of the ferruginous dolomite is the lowest with an average value of $88.2^{\circ} \mathrm{C}$, the formation temperature of calcite is the highest with an average value of $122.6^{\circ} \mathrm{C}$, and the formation temperature of the dolomite is in between with an average value of $108.6^{\circ} \mathrm{C}$. The full-filled fracture serve as a barrier for fluid flow whereas the semi-filling fractures and small-filling fractures provide a channel for hydrocarbon migration and accumulation, and the semi-filling fractures can be kept open for a long time because of occurring of fracture fillings whereas the small-filling fractures may be closed due to dropping of pressure in the stages of exploitation.

Key words: Fracture fillings, tight sandstones, tectonic fluids, Tarim Basin 